\title{
Sustainable Companies, Addressing Climate Change. A Theoretical Review
}

\author{
PhD Carmen Echazarreta Soler ${ }^{1}$, PdD Student Albert Costa Marcé $^{1}$ \\ ${ }^{1}$ Universitat de Girona, Spain \\ Correspondence: Carmen Echazarreta Soler, Universitat de Girona; Albert Costa Marcé, Universitat de Girona, St. \\ Domènec. Pl. Ferrater Mora, 1, Office 518, 17071 Girona, Spain. E-mail: carmen.echazarreta@udg.edu; \\ albert.costa@udg.edu
}

Received: January 4, 2018

Accepted: February 21, 2018

Online Published: February 23, 2018

doi:10.11114/bms.v4i1.2911

URL: https://doi.org/10.11114/bms.v4i1.2911

\begin{abstract}
Climate change is an unavoidable threat with potentially irreversible effects. In the current economic context, globalization significantly increases the unbalanced use of finite, non-renewable sources of energy. This study aims to describe the main characteristics of sustainable companies, based on ideals and values that are committed to the development of the planet, consuming fewer resources than those that they create. Sustainable companies are based on fundamental principles such as the environment (renewable energy resources, sustainable development, preservation of the environment, responsible energy use, minimization of emissions, eco-efficiency, and the circular economy) and mobility (collective public transport, electric vehicles, clean non-motorized mobility systems). In light of this situation, a number of improvement actions have been proposed aimed at sustainable business development (smart environmental sensor networks, energy efficiency, integrated water cycle management, efficient lighting, smart metering, smart irrigation, environmental protection, smart waste management, smart public transport, monitoring of tolls and access to restricted areas, traffic management, fleet management, smart parking, and electric vehicles). Following a theoretical review of the main related studies, it is concluded that there are gaps in information and research related to climate change. At the same time, a further conclusion is that the instruments currently used to mitigate its effects are insufficient and inadequate. Greater indexes of governance and transnational strategy are urgently needed. Finally, there is also a need for sustainable companies that combine business development with the environment and the protection of the planet.
\end{abstract}

Keywords: sustainable companies, environment, climate change, environmental degradation, waste generation, sustainable development, mobility

\section{Introduction}

According to the Paris Agreement pursuant to the Framework Convention on Climate Change organized by the United Nations, "climate change represents an urgent and potentially irreversible threat to human societies and the planet and thus requires the widest possible cooperation by all countries, and their participation in an effective and appropriate international response, with a view to accelerating the reduction of global greenhouse gas emissions". The UN therefore proposes "holding the increase in the global average temperature to well below $2^{\circ} \mathrm{C}$ above pre-industrial levels and to pursue efforts to limit the temperature increase to $1.5^{\circ} \mathrm{C}$ above pre-industrial levels, recognizing that this would significantly reduce the risks and impacts of climate change". (United Nations, 2015).

In this respect, according to Kramers, Höjer, Lövehagen, and Wangel (2013), variability in rainfall can put the supply of fresh water at risk, affecting more than $40 \%$ of the world population. In addition, the increase in carbon dioxide emissions has harmful effects on all of the planet's ecosystems. According to Eguiguren (2011), to combat the effects of climate change through the sustainable development of companies: "A sustainable human system or behaviour is required, committed to the harmonious development of the planet and of humanity which, acting out of a full sense of responsibility, contributes to the wealth and the common good and does not consume more resources than it generates".

The growing threat implicit in a new economic market, marked by the emergence of countries with low production costs, has led companies to adopt ever more competitive strategies. Companies adopt delocalization processes as a means to reduce production costs; however, transport costs and the use of less efficient technology (García, Mora, \& 
Alés, 2009) result in increased energy consumption. To counteract this form of growth, large reductions in worldwide emissions are needed to urgently confront climate change.

Economic and financial crises are ever more frequent, profound and global, and their effects are felt mainly in social sectors (Hadad Hadad \& Valdés Llanes, 2010). Furthermore, climate change is a common concern of humanity; both cases call for measures that respect, promote and take into account obligations on "human rights, the right to health, the rights of indigenous peoples, local communities, migrants, children, persons with disabilities and people in vulnerable situations and the right to development, as well as gender equality, empowerment of women and intergenerational equity" (United-Nations, 2015).

In this context, the private sector must adopt measures to combat climate change (Laszlo, 2003). The management of companies requires corporate policies and values that stem from a business culture that is environmentally sustainable. Companies whose mission is based on ideas and values that are committed to the planet contribute to the common good and, at the same time, may produce profits that are similar to other companies (Eguiguren, 2011).

Noting the importance of guaranteeing the integrity of all ecosystems and the protection of biodiversity, business models emerge that are alternatives to capitalist models, such as People, Planet and Profit (3P), developed by Fisk (2010), which suggests that the deficiencies of the current model can be overcome by establishing links between the social, environmental, corporate and economic spheres.

According to Klionsky et al. (2012), sustainable companies act in the market through a sense of responsibility, transparency, democracy, participation and ethics. Additionally, they are created in environments that recognize the need to promote sustainable energies.

This theoretical review aims to show the result of a systematic selection of relevant research into concepts linked with companies and sustainability and to lay the scientific foundations for the definition of an alternative model of creating, leading and managing companies.

\section{Sustainable Companies}

In 2012 the United Nations carried out a survey to ascertain the opinions held by citizens regarding the challenges facing humanity. This led to world leaders agreeing Sustainable Development Goals (SDG), a set of 17 goals and 169 targets to be met by 2030. On the environmental level, the following stand out: a) Clean water and sanitation; b) Accessible, non-polluting energy; c) Sustainable cities and communities; d) responsible production and consumption; e) Action on climate; f) Underwater life, and; g) The life of terrestrial ecosystems.

In line with such goals, Kramers et al. (2013) proposed that sustainable companies are based on two fundamental principles. The first of these is the environment, defined as the control of the carbon footprint and greenhouse gas emissions (GHG); the monitoring and control of contamination and improvement of air quality; the generation of waste and pollution; environmental sustainability; the efficiency, reuse and recycling of resources; the promotion of renewable energies and improvement of conventional energy; the reduction of water consumption; improvements in air-conditioning and heating; and promotion of green areas. The second is mobility, in the sense of reducing emissions of polluting gases; and efficient, clean and multi-modal transport.

\subsection{Environment}

The first signs of environmental degradation appeared in Europe towards the end of the 1960s, and this spurred the international community to question an economic model in which industry appropriates the natural world, over-exploiting non-renewable natural resources, and leading to the current environmental situation (Kramers et al., 2013).

Globalization significantly increases the imbalanced use of finite, non-renewable energy sources (fossil fuels such as oil, coal and natural gas; and radioactive isotopes such as uranium and plutonium). Various studies have concluded that, should consumption continue at current rates, finite energy sources will run out in 2050. As a response to this situation, environmental sustainability as the axis of counter-globalization is at the heart of the World Social Forum, held annually by a range of social movements; it celebrates diversity, discusses relevant subjects and seeks solutions to social problems that arise from neo-liberalism and economic globalization (Kuklinski, 2007).

Secondly, as argued Quesada (2009), the sustainability of the planet is further put at risk by climate change. He analyses the main effects of climate change, among which are rising sea-levels, heat waves, violent storms, drought, the extinction of species, disease, and the melting of glaciers. He also highlights government-led measures that favour sustainable development such as the Kyoto Protocol on Climate Change and even make them more ambitious before 2020; the Spanish Government's National Plan on Emission Allocation; and, most specifically, the Paris Agreement of 11th December 2015 in the Framework Convention on Climate Change. 
A third subject that, according to Arroyave Rojas y Garcés Giraldo (2012), should be approached is waste generation, in particular greenhouse gas emissions, highlighting increases in nitrogen oxides, carbon dioxide and methane, along with aspects that cause further problems, such as deforestation. Waste adds an extra cost to the production process, as it implies poor use of raw materials; furthermore, treatment costs and deterioration in the quality of life also result in significant economic, environmental and social impact. The main techniques to minimize waste and prevent pollution can be divided into four groups. These are, the most accurate inventory possible of products; modification of production processes; reduction of volume of waste, and; waste recovery.

Fourthly, the WHO states that atmospheric pollution is the main environmental risk factor in avoidable death. The air we breathe should be as clean as possible; this involves an effort to control the maximum limits of sulphur dioxide, nitrogen dioxide, particles, lead, benzene and carbon monoxide.

Governments first proposed zero growth measures, under which pollution and recycling levels would be the same, contributing to an ecological balance. Numerous policies were introduced creating recycling systems that would be funded by those who polluted. The general public were made aware of the problem by contributing to the cost of recycling, funding this ecological balance.

Such a proposal is, however, technically utopian, as many existing resources can neither be renewed nor recycled; it would thus also result in harm to the environment, albeit slower. The idea of placing a value on natural resources and maintaining sustainable development was consequently discarded (Calomarde José, 2000).

The World Commission on Environment and Development produced the concept of sustainable development, by which economic progress should meet current energy needs without compromising those of the future. It is, thus, about making management of natural resources, the positive impact on the environment and the promotion and care of nature all compatible with economic development.

In stabilised, balanced natural surroundings, business development should be compatible with the environment and protection of the planet through sustainable development.

According to the guidelines of Eguiguren (2011), sustainable companies should seriously confront a wide range of subjects, that go from the optimisation of natural resources to the handling of waste, to training and raising awareness of staff, clients and suppliers. While this is regulated in most countries, every organisation should constantly assess the environmental impact of their actions.

An organisation can only be considered sustainable if it commits itself to the balanced development of the planet, producing neutral activity; by this we mean that it respects ecosystems and that its activity consumes only those resources strictly necessary and, in no case more than those it generates. The use of the 'three Rs' is recommended: reduction of emissions of $\mathrm{CO} 2$ and other greenhouse gases; recycling of waste for later use in other activities or production processes; and recovery of other resources, fomenting the use of renewable energies (Roseland, 2012).

Actions aimed at preserving the environment will also be important in two areas, such as water consumption and food. There should be research into and promotion of techniques that aid in growing crops that need less water, fewer chemical composts and pesticides. Agriculture could then develop in parts of the planet where there is little water and fertilizer. At the same time, dietary habits need to be changed, away from high-calorie, animal fat and protein based diets to others balanced with vegetable proteins, since these use fewer natural resources and are generally more accessible (Engel, Pagiola, \& Wunder, 2008).

In this context, according to Wackernagel y Rees (1998) the ecological footprint is the indicator of the environmental impact of human demand of the resources available in the Earth's different ecosystems. Companies increasingly manufacture products with a large number of parts that can be reused, thus consuming fewer non-renewable materials and energies. There is a growth in the use of renewable vegetal material that requires less fossil fuel in its production.

The corporate ecological footprint is an indicator that can be applied to companies and organizations that can result in a framework for the analysis of bio-productive demand. Data is collected for analysis in variables such as a) energy consumption and intensity, b) natural productivity; c) energy production capacity; d) equivalence factor; e) electricity consumption; f) fuel consumption; g) material consumption (general, in construction and depreciable); h) service consumption, waste emissions and discharges; i) solid waste; $\mathrm{j}$ ) emissions into the atmosphere and discharges; $\mathrm{k}$ ) consumption of agricultural resources; l) food; $\mathrm{m}$ ) consumption of timber resources; $\mathrm{n}$ ) land use; o) $\mathrm{CO} 2$ emissions and carbon footprint; p) eco-efficiency; q) social and cultural footprint (Barrett \& Scott, 2001).

Alongside this, there are a large number of industries who aim to minimise emissions. Symbiotic industries are established where the waste produced by other companies and towns is used as the raw material in other production processes. Water in particular is one of the resources most affected over recent decades; vast resources have been required to mitigate the devastating impact of indiscriminate over-exploitation and gradual pollution. 
As a result of the United Nations Framework Convention on Climate Change of Paris, 114 multinationals, among them Enel, Sony, Procter \& Gamble, Thalys, Ikea, Carrefour, Kellogg and Wal-Mart have jointly agreed goals to reduce their emission of greenhouse gases in two years, thus keeping global warming at $2^{\circ} \mathrm{C}$.

Sustainable companies increase the use of renewable or alternative natural energy. Such energy is endless or can be naturally regenerated, and includes hydraulic, thermal solar, biomass, solar, wind, geothermal and marine energies.

This context has also seen the emergence of eco-efficiency in the use of fuels such as biomass (timber, agricultural waste, and manure) that can provide energy that substitutes fossil fuels. As fossil fuel use in transport and logistics is highly polluting, policies are called for that realign rural areas and cities. Their transformation into ecologically better balanced systems is vital in order to reduce CO2 emissions, (Kramers et al., 2013).

Biomass can include liquid agro-fuels such as biodiesel or bio ethanol; gases, such as methane; and solids, like timber. Reaching a balance evidently does not involve using more biomass than that produced by the ecosystem exploited. Developed technologies and recyclable materials should help avoid desertification and contamination of the planet.

A further aspect that should be highlighted is the consumption of eco-efficient materials. An example can be found in construction, where there is an increasing use of materials such as decontaminant cement, natural hydraulic lime, transparent cement, etc. in building and restoration work. Eco-efficient materials normally withstand the weather better, they are logistically cheaper and respect the natural surroundings. On buying such material, the ecological label should be identified and assessed, and the material used in the manufacture of vehicles and computers should taken into account on purchasing them.

When companies provide a service, they should emphasize eco-efficiency in aspects such as waste reduction, land use, the consumption of agricultural, marine, timber and water resources, the analysis of possible water loss and leaks as well as promoting the use of rain water in irrigation (Passetti \& Tenucci, 2016).

A notable variable is natural capital. According to Fisk (2010) this refers to those natural resources of the planet and biosphere such as plants, air, oil, animals or minerals that, by producing oxygen, naturally purifying water and preventing erosion and pollination, act as natural ways of producing eco-system goods as they. Examples of natural capital that a company can invest in are a) woodland capital (the natural reduction of $\mathrm{CO} 2$ by forests); b) agricultural capital (sustainable farms, ecological agriculture and energy crops, or; c) marine and fishing capital. The recommendation of the United-Nations (2015) is for the use of "positive incentives for reducing emissions from deforestation and forest degradation, and the role of conservation, sustainable management of forests and enhancement of forest carbon stocks; as well as alternative policy approaches, such as joint mitigation and adaptation approaches for the integral and sustainable management of forests".

The sea is also taken to be natural capital, the decline of the fishing industry can be combated through measures for marine development and sustainable fishing.

In the current context, the linear economic model of "take, make, dispose" requires large amounts of energy and other cheap, easily accessible resources; it is, however, reaching the limit of its capacity. In contrast, the circular economy, a model developed by MacArthur (2013), is an alternative based on the principles of "repair and regeneration"; its goal is for products, parts and resources in general to maintain their usefulness and value at all times.

For example, in the linear economy, companies purchase machinery that is amortized over a useful life of four to five years, producing waste that is difficult to reuse and recycle. Under the circular economy, companies purchase the use of machinery. This paradigm shift means that the company supplying the service is responsible for and has the greatest interest in lengthening the useful life of its machinery, through repairs and using longer lasting parts that offer better performance.

The circular economy proposes a continuous cycle of positive development that preserves and improves natural capital, optimizing the use of resources and minimizing the risks of the system through managing a finite quantity of resources and non-renewable flow.

According to Ghisellini, Cialani, y Ulgiati (2016), the circular economy is based on three key principles: to preserve and improve natural capital; optimize resource use; and promote the efficiency of the system. Products are designed so that they can later be taken apart and readapted. As the materials used are non-toxic, they can be easily composted. Artificial materials, polymers or alloys, are designed to be reused with minimum energy and maximum quality. The restorative circular economy means a significant reduction in the energy needed for it to work, in turn permitting the exclusive use of renewable energies. Among the companies that are researching and implementing circular economy systems are Cisco, Google, H\&M, King Fisher, Philips, Renault and Unilever. Below are a series of measures linked with key environmental concepts that are developed and applied in sustainable companies (Kramers et al., 2013). (See table 1): 
Table 1. Actions of sustainable companies regarding various concepts linked to the environment (Adapted from Barcelona-City-Council (2012)

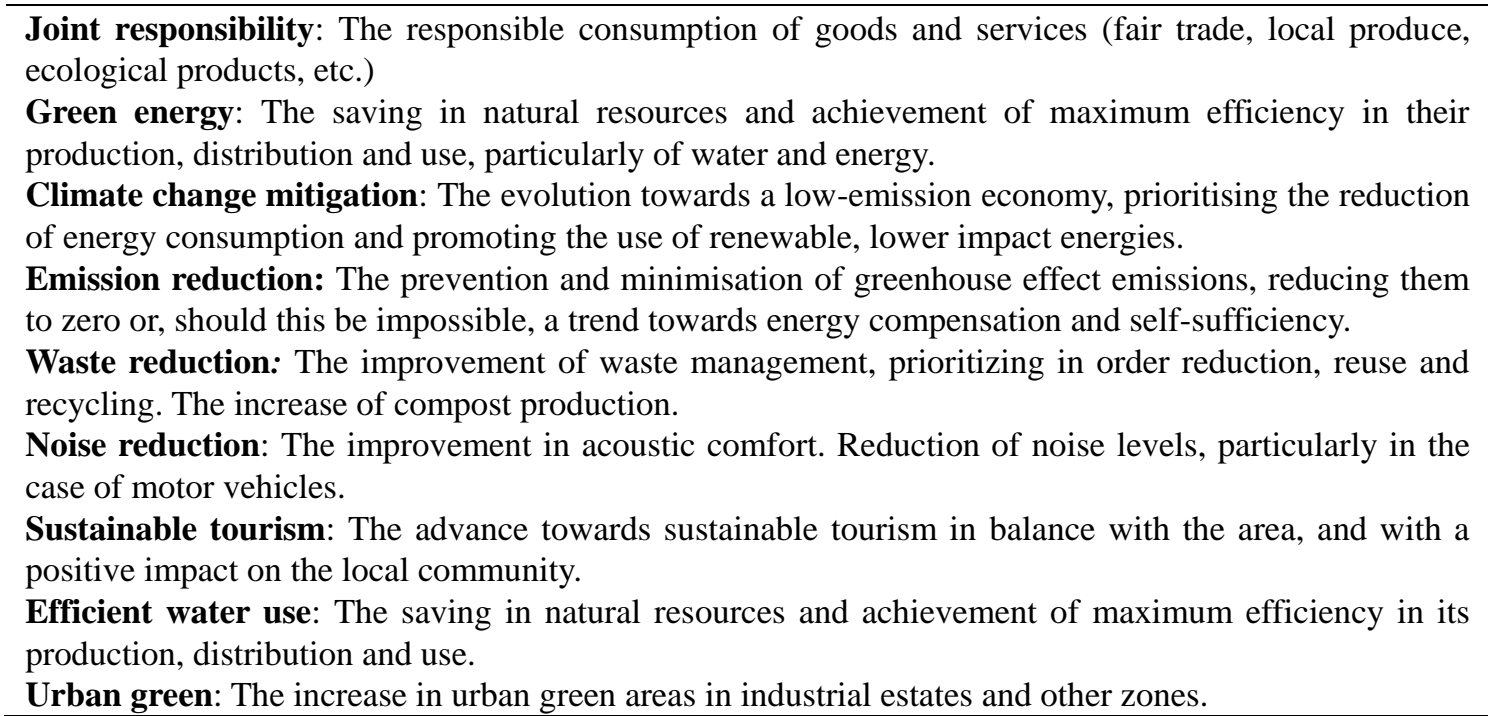

\subsection{Mobility}

In order to progress towards an effective logistical and transport system that is safe, sustainable, interlinked, integrated and of low environmental impact, companies will have to gradually renounce those vehicles in their fleet that contaminate, thus contributing to the reduction of industrial pollution (Seisdedos et al., 2015a).

On a global level, the strategic implementation of low-emission industrial zones is needed, as are environmental taxation laws and a range of toll fees that depend on the contamination produced by different vehicles. Such measures promote the introduction into fleets of electric vehicles, or those whose level of emissions is very low; they also contribute to the more widespread use of alternatives to vehicles, such as travelling to and from work by bicycle or public transport (Kramers et al., 2013).

Improving the air that we breathe is an opportunity to reindustrialize the country using the best available technologies, to reduce dependence on oil, foment the electrification of road transport and take the definitive step towards high quality, competitive public transport (Ke et al., 2016).

Kim, Kabir, y Kabir (2015) concludes that road transport is the main source of pollution, both of nitrogen oxides and suspended particles. The increasing amount of traffic and dieselization are the prime causes. An example that was widely reported in the media is that of the accusation made by the Environmental Protection Agency of the USA against Volkswagen of having violated the Clean Air Act. The German car maker was accused of having installed a software system in its four-cylinder diesel vehicles that circumvented regulations on the emissions of certain air-polluting elements, such as carbon dioxide. A number of studies have shown that these vehicles emit pollution up to 40 times above the legal limit.

According to Mollinedo (2014), industrial zones should promote the improvement in conditions of urban mobility and favour rational mobility. Collective public transport (metro, bus, rail, tram, etc.) should be convenient, interconnected with the urban network, frequent and economically competitive. The introduction of special fares is also recommended in order to increase the use of transport and reduce pollution. Users must receive useful, real-time information so that they can save time, change transport easily and contribute to reducing the carbon footprint. Users should also be enabled to give feedback on public transport systems which should then lead to improvements.

Air quality can be improved through a reduction in the number of vehicles on the road and a move towards a low emission mobility model, prioritising electric vehicles as these are currently the only vehicles that produce zero emissions. Measures include rebates in local parking fees, the exemption from paying increased tolls and a rebate in the atmospheric contamination tax, among others.

Buehler and Pucher (2012), say that what is needed is a return to clean, non-motorised systems of mobility for the journeys to and from work, such as by bicycle and on foot. The authors suggest that companies support industrial estates with interconnected infrastructures for daily pedestrian and bicycle traffic.

Ports and airports are fundamental logistical infrastructures, fulfilling commercial, passenger, logistic and energy functions. In such places, the use of Liquefied Natural Gas (LNG) should be fomented along with other fuels as 
alternatives to the use of hydrocarbons in boats, heavy goods vehicles and machinery (Dameri \& Garelli, 2014).

An example of good practice is Saba, one of Europe's largest operators of car parks. CSR is a central part of its management and promotes a) sustainable mobility (the use of automatic electronic payment), and a mobility management model in urban areas; b) energy efficiency and carbon footprint, c) an integrated waste management and reduced consumption system; d) fleets of electric vehicles, and; e) the integration of disabled people in the workforce.

Below is a series of key mobility-related concepts that are developed and applied in sustainable companies (Kramers et al., 2013). (See table 2):

Table 2. Actions of sustainable companies regarding various concepts linked to mobility

Cleaner air: To improve air quality, particularly regarding nitrogen oxides, suspended particles and allergens. Reduction of motorized traffic, promoting less contaminating fuel and electric vehicles. Promoting the safe use of bicycles. Access to a larger fleet of public transport. Introduction of electric vehicles, prioritising sources of renewable energy.

Equitable mobility: To improve universal access to public transport, buildings and spaces, eliminating unnecessary barriers and organising parking. Promotion of non-motorised journeys. Improvement of pedestrian areas.

Sustainable mobility: The promotion of strategies that discourage the use of private motorised vehicles. Promotion of efficient driving. Adapted from Barcelona-City-Council (2012)

2.3 Actions Aimed at Developing Sustainability in Companies

According to Passetti y Tenucci (2016) present and future support for sustainable development opens the way to a new political and business ethics. In this context, a shortage of resources can be combated through eco-efficiency, which is the production of more consumer goods and services using fewer resources and creating less waste and pollution. Eco-efficiency can be applied in the use of conventional energy, such as electricity, or in alternative, renewable or green, energies; it can even apply to all energy that does not involve the burning of fossil fuels such as coal, gas and oil. This wide definition also includes nuclear and hydro-electric energy.

Below is a proposal for improvement actions related to a sustainable business management (Seisdedos et al., 2015b). (See Table 3):

Table 3. Actions aimed at developing sustainability in companies

\section{- Smart environmental sensor networks (automatic detection of noise levels and noise pollution) \\ - Energy efficiency (use of high energy efficiency equipment - cogeneration, high efficiency boilers, home automation - and solutions that promote energy consumption management in air conditioning,} lighting and elevators...

- Management of the entire water cycle (use of technology to make water a closed cycle: collection, transportation, distribution, sewerage, consumption reading, billing, payment collection, treatment and purification,...)

- Efficient lighting (use of LED technology, smart, on-demand or presence sensing lighting systems)

- Smart metering (telemetering of water, gas and electricity consumption, providing better information that favours savings and efficiency in consumption)

- Smart irrigation (automation of irrigation and sensor networks to measure when and how much irrigation is required)

- Environmental protection (detection of and reaction to environmental emergencies: leaks, fires, etc...)

- Smart waste management (real-time information on fullness levels of garbage containers; dynamic programming according to garbage truck routes, etc...)

- Smart public transport (priority for public transport at traffic lights, integrated management of fares between bus, subway, and suburban rail network, real-time information on incidents and frequencies, digital advisory services for travellers, etc.)

- Monitoring of tolls / access to restricted areas (automatic identification of authorized vehicles, automated charge for using toll roads,...)

- Traffic management (traffic prediction, smart traffic lights, real-time information for drivers, notices about incidents, digital advice services to drivers, etc.)

- Fleet management (ecological propulsion vehicles, real-time GPS localization, digital management and tracking of consumption, performance reports, maintenance management, etc.)

- Smart parking (real-time information on availability of parking spaces, reservation of spaces online, variable parking rates, etc.)

- Electric vehicle (vehicle charging networks, information systems for location and availability, public rental systems for electric vehicles, etc.) 


\section{By Way of Conclusion}

The conclusion, after having analysed a range of previous studies into sustainable companies, is that they may be a useful alternative with which to overcome the deficiencies presented by the current energy model, providing a progressive and efficient solution to the pressing threat of climate change.

The study assesses the approval of the Paris Agreement on Climate Change by 195 countries, which sets a limit to the emission of greenhouse gases, establishes a funding system, as well as measures to combat climate change. In line with the summit's conclusions, the axes that are deemed determining for the environment and mobility are: "(a) Holding the increase in the global average temperature to well below $2{ }^{\circ} \mathrm{C}$ above pre-industrial levels and to pursue efforts to limit the temperature increase to $1.5^{\circ} \mathrm{C}$ above pre-industrial levels, recognizing that this would significantly reduce the risks and impacts of climate change; (b) Increasing the ability to adapt to the adverse impacts of climate change and foster climate resilience and low greenhouse gas emissions development".

The studies analysed highlight firstly the need for an in-depth analysis of companies that are based on such factors as being smart and inclusive, both of which are necessary complements to sustainability. According to (Seisdedos et al., 2015b), "The challenge for companies is to make economic development, respect for the planet and a better quality of life compatible with one another. As in other sectors, information and communication technologies are giving rise to smart management. Like cities, companies are responsible for most of the environmental impact made by human beings. They are large consumers of natural resources (water, energy, raw materials, ...) and generate huge amounts of waste."

Secondly, in order to create, lead and manage companies that have a value, a smart, sustainable and inclusive integrating model based on joint responsibility, green energy, climate change mitigation, emission, waste and noise reduction, sustainable tourism, efficient water use and urban green. The present theoretical review takes into account the global commitments of the United Nations Framework Convention on Climate Change of Paris (United Nations, 2015); the Kyoto Protocol: International Convention on Preventing Climate Change; models such as People, Planet Profit, by Fisk (2010) and Eguiguren (2011) are interesting studies.

Thirdly, scientific studies are needed that define qualitative and quantitative indicators to assess this new model through the use of new technologies which, as Seisdedos et al. (2015b) conclude, may be summarized as follows: a) Smart environmental sensor networks; b) Energy efficiency; c) Integrated water cycle management; d) Efficient lighting; e) Smart metering; f) Smart irrigation; g) Environmental protection; h) Smart waste management; i) Smart public transport; j) Monitoring of tolls and access to restricted areas; k) Traffic management; l) Fleet management; m) Smart parking, and n) Electric vehicles.

Finally, experimental studies are required that can assess the results of the introduction of this model. The development of didactic content and informative and training material is recommended to raise the awareness of and train the public in general as well as staff, suppliers and clients.

The results of this study are preliminary and have to be confirmed through further analysis. Research in this field should be continuous and multi-disciplinary.

\section{References}

Arroyave, R. J. A., \& Garcés, G. L. F. (2012). Tecnologías ambientalmente sostenibles.

Barcelona-City-Council. (2012). Citizen commitment to sustainability 2012-2022. For a more equitable, prosperous and self-sufficient barcelona.

Barrett, J., \& Scott, A. (2001). The ecological footprint: a metric for corporate sustainability. Corporate Environmental Strategy, 8(4), 316-325. https://doi.org/10.1016/S1066-7938(01)00132-4

Buehler, R., \& Pucher, J. (2012). Cycling to work in 90 large American cities: new evidence on the role of bike paths and lanes. Transportation, 39(2), 409-432. https://doi.org/10.1007/s11116-011-9355-8

Calomarde, J. V. (2000). Marketing ecológico. Madrid: Editorial Pirámide.

Dameri, R. P., \& Garelli, R. (2014). Measuring Business Benefits and Performance in Smart Cities. Paper presented at the 9th European Conference on Innovation and Entrepreneurship: ECIE2014.

Eguiguren, M. (2011). Empresa 3.0 Políticas y valores corporativos en una cultura empresarial sostenible: Madrid: Pirámide.

Engel, S., Pagiola, S., \& Wunder, S. (2008). Designing payments for environmental services in theory and practice: An overview of the issues. Ecological economics, 65(4), 663-674. https://doi.org/10.1016/j.ecolecon.2008.03.011

Fisk, P. (2010). People planet profit: How to embrace sustainability for innovation and business growth: Kogan Page Publishers. 
García, B. F., Mora, C. M., \& Alés, G. P. (2009). Las estrategias de competitividad de la industria del calzado ante la globalización. Revista de estudios regionales, (86), 71-96.

Ghisellini, P., Cialani, C., \& Ulgiati, S. (2016). A review on circular economy: the expected transition to a balanced interplay of environmental and economic systems. Journal of Cleaner production, 114, 11-32. https://doi.org/10.1016/j.jclepro.2015.09.007

Hadad, H. J. L., \& Valdés, L. E. (2010). La protección social en salud como enfrentamiento a una crisis económica. Revista Cubana de Salud Pública, 36(3), 235-248. https://doi.org/10.1590/S0864-34662010000300008

Ke, W., Zhang, S., Wu, Y., Zhao, B., Wang, S., \& Hao, J. (2016). Assessing the future vehicle fleet electrification: The impacts on regional and urban air quality. Environmental Science \& Technology, 51(2), 1007-1016. https://doi.org/10.1021/acs.est.6b04253

Kim, K. H., Kabir, E., \& Kabir, S. (2015). A review on the human health impact of airborne particulate matter. Environment international, 74, 136-143. https://doi.org/10.1016/j.envint.2014.10.005

Klionsky, D. J., Abdalla, F. C., Abeliovich, H., Abraham, R. T., Acevedo, A. A., Adeli, K., ... \& Aguirre, G. J. A. (2012). Guidelines for the use and interpretation of assays for monitoring autophagy. Autophagy, 8(4), 445-544. https://doi.org/10.4161/auto.19496

Kramers, A., Höjer, M., Lövehagen, N., \& Wangel, J. (2013). ICT for Sustainable Cities: How ICT can support an environmentally sustainable development in cities. Paper presented at the ICT4S 2013: Proceedings of the First International Conference on Information and Communication Technologies for Sustainability, ETH Zurich.

Kuklinski, H. P. (2007). Planeta Web 2.0. Inteligencia colectiva o medios fast food (Vol. 1): LMI.

Laszlo, C. (2003). The sustainable company: How to create lasting value through social and environmental performance: Island Press.

MacArthur, E. (2013). Towards the circular economy.

Mollinedo, C. L. (2014). Movilidad urbana sostenible: un reto para las ciudades del siglo XXI. Revista Economía, Sociedad y Territorio, 6(22).

Passetti, E., \& Tenucci, A. (2016). Eco-efficiency measurement and the influence of organisational factors: evidence from large Italian companies. Journal of Cleaner production, 122, 228-239. https://doi.org/10.1016/j.jclepro.2016.02.035

Quesada, J. L. D. (2009). Huella ecológica y desarrollo sostenible: Asociación española de normalización y certificación ed.

Roseland, M. (2012). Toward sustainable communities: Solutions for citizens and their governments (Vol. 6): New Society Publishers.

Seisdedos, G., Richart, B., Gallego, G., Paz, J. d., Esponera, J., \& Kolotouchkina, O. (2015a). Smart Cities: La transformación digital de las ciudades Centro de Innovación del Sector Público de PwC e IE Business School.

Seisdedos, G., Richart, B., Gallego, G., Paz, J. d., Esponera, J., \& Kolotouchkina, O. (2015b). Smart Cities: La transformación digital de las ciudades Centro de Innovación del Sector Público de PwC e IE Business School.

United-Nations. (2015). Framework Convention on Climate Change: Adoption of the Paris Agreement. FCCC/CP/2015/L.9.

Wackernagel, M., \& Rees, W. (1998). Our ecological footprint: reducing human impact on the earth (Vol. 9): New Society Publishers.

\section{Copyrights}

Copyright for this article is retained by the author(s), with first publication rights granted to the journal.

This is an open-access article distributed under the terms and conditions of the Creative Commons Attribution license which permits unrestricted use, distribution, and reproduction in any medium, provided the original work is properly cited. 